\title{
Mental rotation under head tilt: Factors influencing the location of the subjective reference frame
}

\author{
MICHAEL C. CORBALLIS, BETH A. NAGOURNEY, LARRY I. SHETZER \\ and GERRY STEFANATOS \\ McGill University, Montreal, Quebec, Canada
}

\begin{abstract}
We report five experiments on the effect of head tilt on the mental rotation of patterns to the "upright." In Experiment 1, subjects rotated alphanumeric characters, displayed within a circular surround. Experiment 2 was similar except that the character was an unfamiliar letter-like symbol. In Experiment 3, subjects again rotated alphanumeric characters, but they were displayed within a rectangular frame tilted $60^{\circ}$ to the right. Experiment 4 was similar, except that the subjects were instructed to rotate the characters to the "upright" defined by the tilted frame. In all four experiments, the subjects performed the task with their heads either upright or tilted $60^{\circ}$. In Experiment 5, subjects had their heads and bodies tilted $90^{\circ}$, and rotated alphanumeric characters displayed within a circular surround. In all except Experiment 4, analysis of response latencies revealed that the subjective vertical lay closer to the gravitational than to the retinal vertical, although it was somewhat displaced in the direction of the head tilt-more so in Experiments 2 and 3 than in Experiment 1, and more so still in Experiment 5. In Experiment 4, instructions to adopt the axes of the frame (and thus of the retina) succeeded in bringing the subjective vertical closer to the retinal than to the gravitational vertical, although the subjective vertical was still some $20^{\circ}$ on average from the gravitational vertical. The results show that the subjective reference frame is distinct from both gravitational and the retinal frames, and that the gravitational frame exerts the stronger influence. They also argue against the primacy of a "retinal factor" in the perception of orientation.
\end{abstract}

In certain tasks involving perceptual judgments about visual patterns, people may "mentally rotate" an internal representation of a pattern before making the judgment (e.g., Cooper \& Shepard, 1973; Shepard $\&$ Metzler, 1971). The notion of mental rotation implies some internal space, or coordinate system, within which the rotation is performed. It is of some interest to enquire whether this subjective space is aligned with retinal space, or whether it corresponds rather to environmental coordinates. For instance, when a subject mentally rotates a pattern to an imagined "upright" position, is the upright parallel to the vertical meridian of the retina, does it correspond to the upright as defined by gravity, or might it lie somewhere in between?

Previous experiments have produced somewhat conflicting information. Corballis and Roldan (1975) reported evidence that when subjects are required to make rapid judgments as to whether dot patterns are symmetrical about a line, they mentally rotate the

This research was supported by the National Research Council of Canada. We also acknowledge the use of the computer-based laboratory of the Department of Psychology, McGill University, which is funded by grants from the F.C.A.C. program of the Quebec Ministry of Education and from the Faculty of Graduate Studies and Research, McGill University. M. C. Corballis is now at the University of Auchland, Auckland, New Zealand. patterns until the line is subjectively vertical before making their judgments. When the subjects performed this task with their heads tilted $45^{\circ}$, the subjective vertical evidently lay closer to the retinal vertical than to the gravitational vertical. Corballis, Zbrodoff, and Roldan (1976) obtained a similar result in an experiment in which subjects judged whether or not dot patterns were repeated about a line. By contrast, these investigators found that when subjects with their heads tilted $60^{\circ}$ were required to judge whether rotated alphanumeric characters were normal or backward, they apparently rotated the characters to the gravitational upright before making their judgments

In the present experiments, we examine further the subjective reference frame that subjects employ when they mentally rotate simple patterns under conditions of head tilt. We were particularly interested in the factors influencing the choice of the subjective vertical. The factors we studied included the nature and tilt of the surrounding frame, the familiarity of the test stimuli, the instructions given to the subjects, and the degree of head tilt.

\section{EXPERIMENT 1}

This was for the most part a replication of the 
experiment on-mental rotation of alphanumeric characters reported by Corballis et al. (1976), in which the subjects performed the task with their heads either upright or tilted about $60^{\circ}$. The principal modification was that the characters were surrounded by a circular frame, in order to minimize visual cues about horizontal and vertical. In the earlier experiment by Corballis et al., cues as to the true horizontal and vertical were available in the surround, although they were not conspicuous.

\section{Method}

Subjects. There were nine subjects, all with normal or corrected vision, drawn from undergraduate classes. ${ }^{1}$

Stimuli. The stimuli were the uppercase letters G, J, and R and the Arabic numerals 2, 5, and 7, constructed from Letraset No. 193 and mounted on double-glass slides. Each character was presented in normal and backward (mirror-reversed) form, in six different angular orientations, ranging fron $0^{\circ}$ to $300^{\circ}$ in $60^{\circ}$ steps clockwise from the upright. There were, therefore, 72 slides in all. These stimuli were rear-projected onto a translucent screen. A large piece of matt-black card, with a circle $13.0 \mathrm{~cm}$ in diameter cut out of it, was placed against the screen, between the screen and the subject, so that the visible part of the screen was circular. The diameter of the circle subtended about $7^{\circ} 25^{\prime}$ at the subjects' eyes, and the characters, which appeared at the center of the circle, subtended about $1^{\circ} 10^{\prime}$.

The slides were placed in a random-access projector. Presentation was controlled by a PDP-11 computer, which selected the slides in random order. Selection was without replacement unless the subject made an error, in which case that slide was presented again later in the sequence.

Procedure. The subjects were tested individually. Each subject sat about $.85 \mathrm{~m}$ in front of the screen with the index fingers of each hand resting lightly on a response button. He/she was instructed to fixate the center of the screen when a warning tone, which lasted $500 \mathrm{msec}$, occurred. The stimulus appeared $1 \mathrm{sec}$ after onset of the warning tone, and the subject was to press the button corresponding to the finger of the preferred hand if the character was a normal version and the other button if it was backward. The character remained on the screen until the subject responded (except that there was an upper limit of $4 \mathrm{sec})$. The subjects were told to respond quickly, but not to sacrifice accuracy for speed. The duration between onset of each stimulus and the subject's response was recorded by the PDP-11 computer.

Each subject was given several free practice trials with his/her head upright until he/she felt comfortable with the task. He/she was then given three sequences of 72 trials, once with the head upright and once each with the head tilted left and right. The head was held in a padded wooden frame to prevent movement during the trials. Under the head-tilt conditions, the head was tilted a few degrees over $60^{\circ}$, so that the retinas would be tilted about $60^{\circ}$ (assuming a slight counterrolling of the eyes in their socketsMiller, 1962). The different conditions of head tilt were counterbalanced according to a 3 by 3 Latin square.

\section{Results}

The mean percentages of errors were $12.0 \%$ with the head tilted left, $8.1 \%$ with the head upright, and $11.7 \%$ with the head tilted right. These error rates are somewhat higher than those in the experiment reported by Corballis et al. (1976), and it is also noteworthy that the estimated rotation rates are somewhat slower (see below).
The latencies for correct responses were subject to analysis of variance. There was a significant difference between normal $(1,017 \mathrm{msec})$ and backward $(1,261 \mathrm{msec})$ characters $[F(1,6)=39.36, p<.001]$. This was of the same order as the difference reported by Corballis et al. (1976), although in this experiment (but not in the earlier one) the difference between versions was confounded with hand preference. There was a significant effect of orientation measured in environmental coordinates $[F(5,30)=51.45, p<.001]$. The interaction between orientation and head tilt was only marginally significant when orientation was measured in environmental coordinates $[\mathrm{F}(10,60)=$ $2.52, \mathrm{p}<.05]$; this is not significant if one adopts the conservative degrees of freedom $(1,6)$ recommended by Winer (1971) for repeated-measurements effects. However, this interaction is highly significant when orientation is measured on presumed retinal coordinates $[F(10,60)=26.84, p<.001]$. Although not quite so clear-cut as the results reported by Corballis et al. (1976), these results suggest that the subjective reference frame for making the judgments was bound more closely to environmental than to retinal coordinates. The latency functions for each condition of head tilt are shown in Figure 1.

In order to obtain more precise estimates of the location of the subjective coordinate system, and also of the incidence and rate of mental rotation, we fitted hypothetical contrasts, representing "ideal" mental

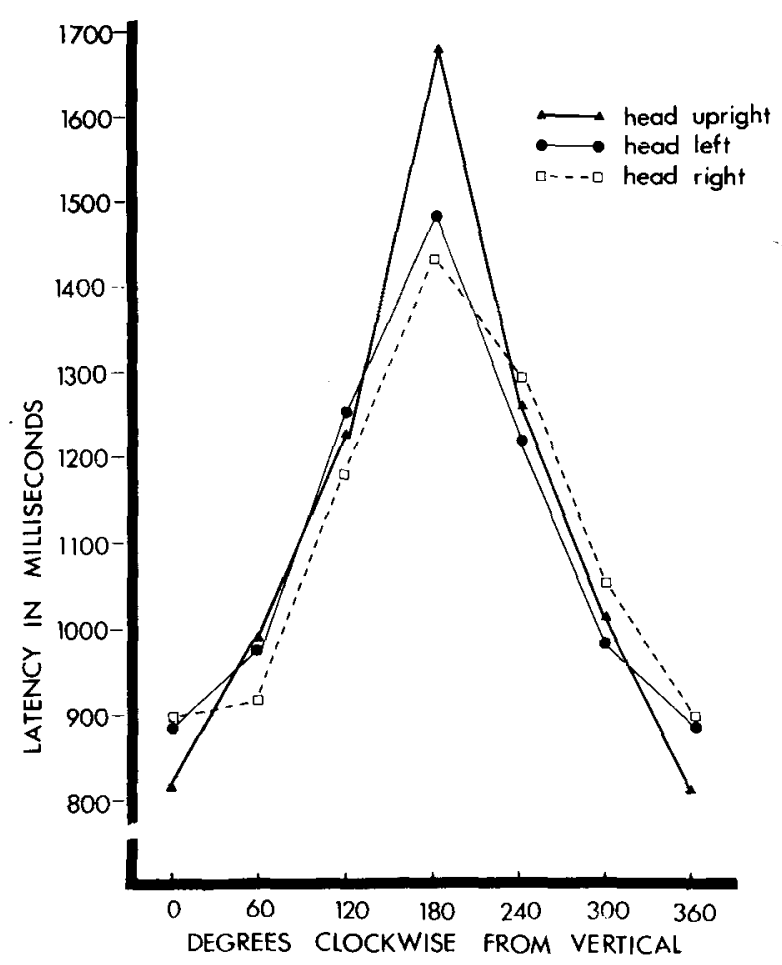

Figure 1. Mean latency as a function of angular orientation of characters for each head tilt in Experiment 1. 
rotation, to the latencies at each orientation. These contrasts incorporated the assumption that latency would be a linear function of angular orientations from the subjective vertical. The actual functions vary, depending upon which sextant of the circle the subjective vertical lies in; for instance, if the subjective vertical is $\theta^{\circ}$ clockwise from the vertical and if $0 \leqslant \theta \leqslant 60$, then we would expect the latencies for characters oriented at $0^{\circ}, 60^{\circ}, 120^{\circ}, 180^{\circ}, 240^{\circ}$, and $300^{\circ}$ clockwise from the vertical to be directly proportional to $\theta,(60-\theta),(120-\theta),(180-\theta),(120+\theta)$, and $(60+\theta)$, respectively. We computed the value of $\theta$ which maximized the variance attributable to the contrast over all possible sextants. The rate of mental rotation was then estimated for this value of $\theta$. The values of $\theta$, rate of mental rotation, and the proportion of variance attributable to the contrast are shown in Table 1, both for the averaged latency function and for the individual functions obtained from each subject.

Analysis of variance revealed that the values of $\theta$

Table 1

Estimates of Proportion of Variance $\left(r^{2}\right)$ Due to Mental Rotation Function, Angular Location $(\theta)$ of Subjective Vertical Measured in Degrees Clockwise from the True Vertical, and Rate of Mental Rotation in Degrees per Second in Experiment 1

\begin{tabular}{|c|c|c|c|c|}
\hline Source & $\begin{array}{c}\text { Head } \\
\text { Position }\end{array}$ & $r^{2}$ & $\theta$ & Rate \\
\hline Subject 1 & $\begin{array}{l}\text { Left } \\
\text { Upright } \\
\text { Right }\end{array}$ & $\begin{array}{l}.976 \\
.745 \\
.756\end{array}$ & $\begin{array}{r}-19.9 \\
-\quad 6.6 \\
19.1\end{array}$ & $\begin{array}{l}234 \\
242 \\
272\end{array}$ \\
\hline Subject 2 & $\begin{array}{l}\text { Left } \\
\text { Upright } \\
\text { Right }\end{array}$ & $\begin{array}{l}.674 \\
.925 \\
.793\end{array}$ & $\begin{array}{r}-15.5 \\
-\quad 7.7 \\
37.1\end{array}$ & $\begin{array}{l}267 \\
149 \\
409\end{array}$ \\
\hline Subject 3 & $\begin{array}{l}\text { Left } \\
\text { Upright } \\
\text { Right }\end{array}$ & $\begin{array}{l}.837 \\
.809 \\
.830\end{array}$ & $\begin{array}{r}4.7 \\
-\quad 4.0 \\
-6.3\end{array}$ & $\begin{array}{l}293 \\
245 \\
191\end{array}$ \\
\hline Subject 4 & $\begin{array}{l}\text { Left } \\
\text { Upright } \\
\text { Right }\end{array}$ & $\begin{array}{l}.848 \\
.910 \\
.786\end{array}$ & $\begin{array}{r}24.0 \\
5.0 \\
16.2\end{array}$ & $\begin{array}{l}143 \\
137 \\
180\end{array}$ \\
\hline Subject 5 & $\begin{array}{l}\text { Left } \\
\text { Upright } \\
\text { Right }\end{array}$ & $\begin{array}{l}.931 \\
.979 \\
.973\end{array}$ & $\begin{array}{r}-15.0 \\
12.3 \\
14.8\end{array}$ & $\begin{array}{l}195 \\
162 \\
173\end{array}$ \\
\hline Subject 6 & $\begin{array}{l}\text { Left } \\
\text { Upright } \\
\text { Right }\end{array}$ & $\begin{array}{l}.920 \\
.810 \\
.929\end{array}$ & $\begin{array}{l}-8.8 \\
-6.8 \\
-9.7\end{array}$ & $\begin{array}{l}298 \\
400 \\
470\end{array}$ \\
\hline Subject 7 & $\begin{array}{l}\text { Left } \\
\text { Upright } \\
\text { Right }\end{array}$ & $\begin{array}{l}.994 \\
.982 \\
.968\end{array}$ & $\begin{array}{l}16.2 \\
14.8 \\
31.2\end{array}$ & $\begin{array}{l}206 \\
165 \\
209\end{array}$ \\
\hline Subject 8 & $\begin{array}{l}\text { Left } \\
\text { Upright } \\
\text { Right }\end{array}$ & $\begin{array}{l}.697 \\
.921 \\
.970\end{array}$ & $\begin{array}{r}2.4 \\
-\quad 3.1 \\
2.8\end{array}$ & $\begin{array}{l}432 \\
223 \\
471\end{array}$ \\
\hline Subject 9 & $\begin{array}{l}\text { Left } \\
\text { Upright } \\
\text { Right }\end{array}$ & $\begin{array}{l}.986 \\
.858 \\
.931\end{array}$ & $\begin{array}{r}-26.1 \\
-16.4 \\
31.2\end{array}$ & $\begin{array}{l}341 \\
479 \\
297\end{array}$ \\
\hline $\begin{array}{l}\text { Averaged } \\
\text { Functions }\end{array}$ & $\begin{array}{l}\text { Left } \\
\text { Upright } \\
\text { Right }\end{array}$ & $\begin{array}{l}.962 \\
.946 \\
.985\end{array}$ & $\begin{array}{r}-3.8 \\
2.0 \\
17.5\end{array}$ & $\begin{array}{l}275 \\
217 \\
259\end{array}$ \\
\hline
\end{tabular}

were significantly influenced by head tilt $[\mathrm{F}(2,16)$ $=5.08, \mathrm{p}<.05$ ], although subsequent paired comparisons using the Newman-Keuls procedure revealed only that the mean value of $\theta$ for right head tilt $\left(15.16^{\circ}\right)$ differed significantly $(p<.05)$ from the other two, which did not differ significantly from each other. Similarly, the value for right head tilt differed significantly $(\mathrm{p}<.05)$ from $0^{\circ}$, but neither of the other values did.

\section{Summary}

It is clear, first, that the hypothesis of mental rotation provides a reasonable fit to the data, not only for the averaged latency functions but for the individual functions as well. It is of some interest that the overall estimates of the rate of mental rotation are lower than the rate of $441^{\circ} / \mathrm{sec}$ which Corballis et al. (1976) estimated from their data, and lower than the average rates reported by Cooper and Shepard (1973). One possible reason for this is that visual cues as to the location of the gravitational vertical were largely eliminated in this experiment. The subjects may therefore have been more uncertain about where to rotate the characters to, and may thus have depended more on visual feedback as to when a rotated representation appeared to be upright. This may have slowed their mental rotation rate.

Even so, it is clear that the subjective vertical lay closer to the gravitational vertical than to the retinal vertical, which confirms the finding of Corballis et al. (1976). There was some variation, however. The largest estimated deviation from the gravitational vertical was $37.1^{\circ}$, obtained from Subject 2 when his head was tilted to the right, but even this deviation is some $23^{\circ}$ away from the retinal vertical. For other subjects, notably Subjects 3,6, and 8 , the subjective vertical was scarcely affected at all by head tilt. Another point of interest is that, overall, the subjective vertical was significantly influenced by head tilt to the right (i.e., clockwise), but not by head tilt to the left. It would perhaps be premature at this time to speculate on the reasons for this effect.

\section{EXPERIMENT 2}

Although Experiment 1 suggested that the subjective vertical may have been slightly influenced by head tilt, it still lay closer to the gravitational than to the retinal vertical. This result still contrasts with the results of experiments on judgments of the symmetry (Corballis \& Roldan, 1975) and repetition (Corballis et al., 1976) of dot patterns about a line, in which the subjective vertical lay closer to the retinal than to the gravitational vertical. One possible factor which might explain the discrepancy is that alphanumeric characters are highly familiar, and subjects are accustomed to seeing them tied to 
gravitational coordinates in the real world, whereas the dot patterns used in the experiments cited above were quite unfamiliar. In the present experiment, therefore, subjects were shown a fairly simple but unfamiliar letter-like symbol in an orientation designated "normal," and were then required to judge whether rotated versions of the symbol were normal or backward.

\section{Method}

Subjects. There were nine subjects, drawn from the same source as in Experiment 1.

Stimuli. The stimuli were derived from a single standard pattern, or symbol, shown in Figure 2. This symbol was photographed in six different angular orientations, ranging from $0^{\circ}$ to $300^{\circ}$ in $60^{\circ}$ steps, and in both normal and reflected form at each angular orientation. There were thus 12 different stimuli. These were projected in the same way as were the alphanumeric characters in Experiment 1. The height of the symbol subtended about $1^{\circ} 35^{\prime}$ at the subject's eyes.

Procedure. The procedure was the same as in Experiment 1, except that the subjects used the index and middle fingers of the preferred hand to press the response buttons. Assignment of fingers to response categories was counterbalanced between subjects. Each stimulus was presented six times per sequence, making 72 trials per sequence (excluding errors), and there were three sequences, one for each condition of head tilt. Test trials did not begin until the subjects expressed confidence that they knew what the symbol looked like.

\section{Results}

The mean percentages of errors were $15 \%$ with the head tilted right, $13 \%$ with the head upright, and $9 \%$ with the head tilted left.

Analysis of variance of latencies for correct responses revealed that the latencies for the "normal" version of the symbol were significantly shorter than those for the backward version $[F(1,6)=16.63$, $\mathrm{p}<.01$ ]; the means were 931 and $1,003 \mathrm{msec}$, respectively. Latencies also varied significantly with angular orientation measured in gravitational coordinates $[F(5,30)=13.58, p<.05]$. Again, the interaction between head tilt and orientation measured gravitationally was significant $[\mathrm{F}(10,60)=4.27$,

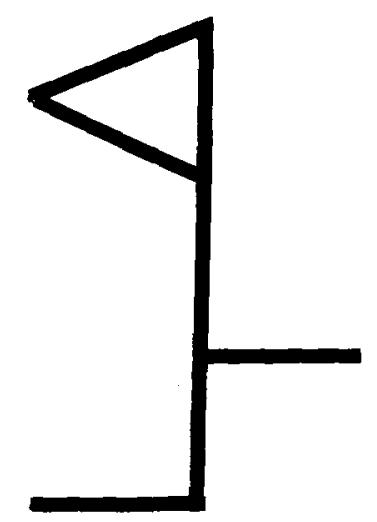

Figure 2. Symbol used in Experiment 2, shown in "upright" orientation and "standard" version.

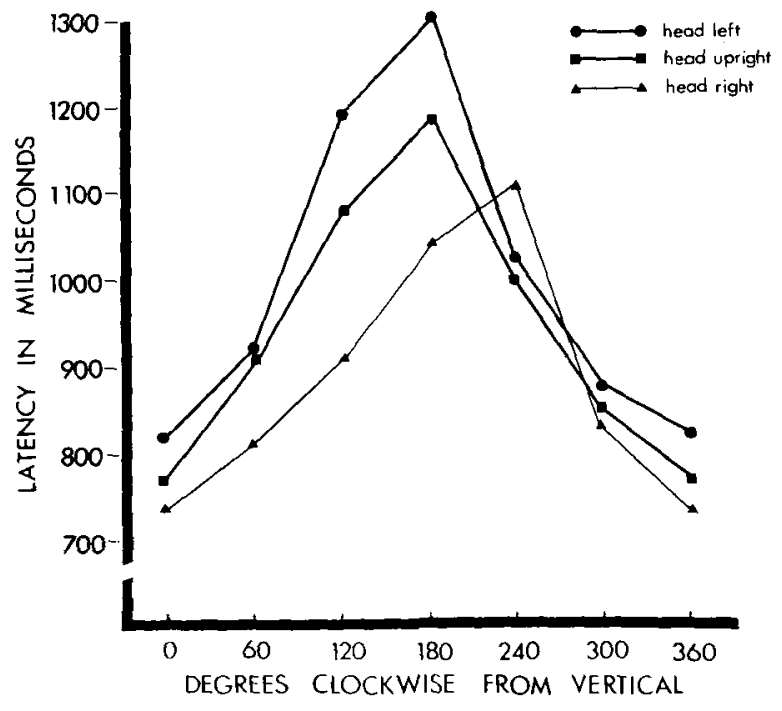

Figure 3. Mean latency as a function of angular orientation of symbol for each bead tilt in Experiment 2.

$\mathrm{p}<.001$ ], unless one adopts conservative degrees of freedom. But if orientation is measured on presumed retinal coordinates, the interaction is significant whether or not one adopts conservative degrees of freedom $[F(10,60)=10.14, p<.001]$. Latencies are plotted as a function of angular orientation for each condition of head tilt in Figure 3.

Mental rotation functions were fitted to the data, as in Experiment 1, and the results are shown in Table 2. The data are for the most part consistent with the proposition that the subjects mentally rotated some internal representation of the symbol to the subjective upright before making their decisions, although there are perhaps some individual exceptions. In particular, Subject 9 and, to a lesser extent, Subjects 2 and 7 produced latency functions which were relatively poorly fit by the functions and which yielded estimated rotation rates which were implausibly high. These subjects may have learned to perform the task without mental rotation on at least some of the trials, perhaps by memorizing what the symbol looked like in the different orientations. But for the rest, and taken overall, the data are generally consistent with the hypothesis of mental rotation, and the estimated rates of rotation are again somewhat lower than those reported in earlier studies (e.g., Cooper \& Shepard, 1973; Corballis et al., 1976).

Analysis of variance again revealed a significant effect of head tilt on the estimates, $\theta$, of the subjective vertical $[\mathrm{F}(2,16)=29.09, \mathrm{p}<.01]$, NewmanKeuls tests showed that the mean value of $\theta$ for right head tilt differed significantly $(p<.01)$ from the means for left head tilt and head upright, but the latter did not differ significantly from each other. However, simple $t$ tests showed that the $\theta$ s for left and 
Table 2

Estimates of Proportion of Variance $\left(r^{2}\right)$ Due to Mental Rotation Function, Angular Location ( $\theta$ ) of Subjective Vertical Measured in Degrees Clockwise from the True Vertical, and Rate of Mental Rotation in Degrees per Second in Experiment 2

\begin{tabular}{|c|c|c|c|c|}
\hline Source & $\begin{array}{c}\text { Head } \\
\text { Position }\end{array}$ & $r^{2}$ & $\theta$ & Rate \\
\hline Subject 1 & $\begin{array}{l}\text { Left } \\
\text { Upright } \\
\text { Right }\end{array}$ & $\begin{array}{l}.828 \\
.876 \\
.743\end{array}$ & $\begin{array}{r}-5.9 \\
1.9 \\
36.9\end{array}$ & $\begin{array}{l}121 \\
247 \\
324\end{array}$ \\
\hline Subject 2 & $\begin{array}{l}\text { Left } \\
\text { Upright } \\
\text { Right }\end{array}$ & $\begin{array}{l}.949 \\
.957 \\
.508\end{array}$ & $\begin{array}{r}-33.1 \\
-17.9 \\
52.9\end{array}$ & $\begin{array}{r}569 \\
921 \\
1,119\end{array}$ \\
\hline Subject 3 & $\begin{array}{l}\text { Left } \\
\text { Upright } \\
\text { Right }\end{array}$ & $\begin{array}{l}.839 \\
.684 \\
.486\end{array}$ & $\begin{array}{r}-46.8 \\
-19.4 \\
13.5\end{array}$ & $\begin{array}{l}263 \\
334 \\
312\end{array}$ \\
\hline Subject 4 & $\begin{array}{l}\text { Left } \\
\text { Upright } \\
\text { Right }\end{array}$ & $\begin{array}{l}.880 \\
.917 \\
.822\end{array}$ & $\begin{array}{r}-9.5 \\
-17.4 \\
20.7\end{array}$ & $\begin{array}{l}210 \\
165 \\
152\end{array}$ \\
\hline Subject 5 & $\begin{array}{l}\text { Left } \\
\text { Upright } \\
\text { Right }\end{array}$ & $\begin{array}{l}.920 \\
.897 \\
.815\end{array}$ & $\begin{array}{r}-38.7 \\
-17.3 \\
19.3\end{array}$ & $\begin{array}{l}367 \\
302 \\
430\end{array}$ \\
\hline Subject 6 & $\begin{array}{l}\text { Left } \\
\text { Upright } \\
\text { Right }\end{array}$ & $\begin{array}{l}.784 \\
.989 \\
.863\end{array}$ & $\begin{array}{r}3.2 \\
-\quad .7 \\
23.6\end{array}$ & $\begin{array}{l}429 \\
561 \\
401\end{array}$ \\
\hline Subject 7 & $\begin{array}{l}\text { Left } \\
\text { Upright } \\
\text { Right }\end{array}$ & $\begin{array}{l}.947 \\
.610 \\
.726\end{array}$ & $\begin{array}{r}-7.4 \\
-44.6 \\
.5\end{array}$ & $\begin{array}{l}362 \\
561 \\
814\end{array}$ \\
\hline Subject 8 & $\begin{array}{l}\text { Left } \\
\text { Upright } \\
\text { Right }\end{array}$ & $\begin{array}{l}.878 \\
.537 \\
.946\end{array}$ & $\begin{array}{r}-8.6 \\
6.3 \\
45.6\end{array}$ & $\begin{array}{l}364 \\
398 \\
442\end{array}$ \\
\hline Subject 9 & $\begin{array}{l}\text { Left } \\
\text { Upright } \\
\text { Right }\end{array}$ & $\begin{array}{l}.772 \\
.607 \\
.516\end{array}$ & $\begin{array}{r}-29.3 \\
-\quad 3.6 \\
51.0\end{array}$ & $\begin{array}{r}1,477 \\
823 \\
2,115\end{array}$ \\
\hline $\begin{array}{l}\text { Averaged } \\
\text { Functions }\end{array}$ & $\begin{array}{l}\text { Left } \\
\text { Upright } \\
\text { Right }\end{array}$ & $\begin{array}{l}.951 \\
.992 \\
.902\end{array}$ & $\begin{array}{r}-16.9 \\
-11.8 \\
25.8\end{array}$ & $\begin{array}{l}302 \\
371 \\
400\end{array}$ \\
\hline
\end{tabular}

right head tilt differed significantly from $0^{\circ}[\mathrm{t}(1,16)$ $=-2.82, \mathrm{p}<.05$, and $\mathrm{t}(1,16)=4.23, \mathrm{p}<.001]$, respectively. Although the results again show that tilting the head to the right affected the subjective vertical more than tilting the head to the left, this should be tempered by the fact that the two most extreme observations for right head tilt were produced by Subjects 2 and 7, whose latencies did not conform well to the hypothesis of mental rotation.

Finally, we wished to test the hypothesis that the subjective vertical would lie closer to the retinal vertical in this experiment than in Experiment 1, since the symbol used in this experiment was unfamiliar compared with the alphanumeric characters used in Experiment 1 (cf. Corballis et al., 1976). For this purpose, we measured $\theta$ in degrees from the gravitational upright toward the retinal upright (i.e., we changed the signs for left head tilt) and computed an analysis of variance in which the independent variables were left vs. right head tilt and Experiment 1 vs. Experiment 2. The effect of head tilt was not significant $[\mathrm{F}(1,16)=3.47]$ and the interaction was negligible, but the departures from the gravitational vertical were significantly greater in Experiment 2 than in Experiment $1[\mathrm{~F}(1,16)=$ $5.60, p<.05]$. This suggests that the subjective vertical did lie closer to the retinal vertical in this experiment, but the effect, though significant, is relatively small.

\section{Summary}

In this experiment, we gained only weak support for the view that the subjective reference frame would be closer to the retinal reference frame when the pattern to be rotated is not one that is normally associated with gravitational coordinates in the everyday world. The subjective vertical was perhaps slightly closer to the retinal vertical than in Experiment 1 , but it still lay closer to the gravitational vertical than to the retinal vertical. The fact that dot patterns were mentally rotated closer to the retinal than to the gravitational vertical in the experiments reported by Corballis and Roldan (1975) and Corballis et al. (1976) may therefore have to do with the complexity of the stimuli rather than with the fact that the stimuli were unfamiliar. Alternatively, it may be that judgments of symmetry and repetition are fundamentally egocentric, so that it is the nature of the task rather than of the stimuli which underlies the discrepancy.

\section{EXPERIMENT 3}

In this experiment, we introduced a tilted rectangular frame onto the projection screen, in order to determine whether this might influence the coordinate system chosen by the subjects in the mental rotation of alphanumeric characters. The frame was tilted $60^{\circ}$ to the right, so that its sides would be approximately horizontal and vertical on the subject's retinal coordinates when the subjects tilted their heads $60^{\circ}$ to the right.

\section{Method}

Subjects. Nine further subjects were drawn from the same source as in the first two experiments. There were four women and five men.

Stimuli. The stimuli and procedure were the same as in Experiment 2 except that a rectangular frame replaced the cardboard with the circular cutout. The frame actually consisted of two rectangles outlined in black, one inside the other. The inner rectangle measured $18 \mathrm{~cm}$ wide $\times 14 \mathrm{~cm}$ high, the outer one $38 \mathrm{~cm}$ wide $\times 30.5 \mathrm{~cm}$ high. Each rectangle was bounded with black tape, $2.50 \mathrm{~cm}$ thick, and the area between the two rectangles was a pale translucent green. The inner rectangle subtended about $10^{\circ} 12^{\prime} \times 6^{\circ} 0^{\prime}$ at the subjects' eyes. The whole frame was tilted $60^{\circ}$ to the right (clockwise).

\section{Results}

The mean percentages of errors were $5.5 \%$ with the head tilted left, $7.1 \%$ with the head upright, and $8.5 \%$ with the head tilted right. 
Analysis of variance of latencies for correct responses once again revealed significant effects due to version $[F(1,6)=42.70, p<.01]$, orientation $[F(5,30)=29.44, p<.01]$, and the interaction between head tilt and orientation $[F(10,60)=4.72$, $\mathrm{p}<.011$ when orientation was measured in gravitational coordinates. The interaction is insignificant, however, if one adopts conservative degrees of freedom $(\mathrm{df}=1,6)$. When orientation is measured in presumed retinal coordinates, the interaction between head tilt and orientation is more highly significant $[F(10,60)=11.75, p<.001]$, indicating again that the subjective coordinate system lay closer to the gravitational one than to the retinal one. The mean latencies are plotted as a function of angular orientation and head tilt in Figure 4.

Estimates of the mental rotation parameters are shown in Table 3. Analysis of variance showed that the estimates of the subjective vertical, $\theta$, were significantly influenced by head tilt $[F(2,16)=26.29$, $\mathrm{p}<.001$ ], and Newman-Keuls tests showed that each of the three paired comparisons was significant $(\mathrm{p}<.01)$.

When the head was tilted to the right, the axes of the frame were approximately aligned with the retinal horizontal and vertical. The values of $\theta$ under this condition differed significantly from $0^{\circ}$ $[\mathrm{t}(18)=5.18, \mathrm{p}<.001]$, but also differed significantly from $60^{\circ}[\mathrm{t}(18)=10.36, \mathrm{p}<.001]$, indicating that the frame did not cause the subjects to adopt a retinal coordinate system and did not itself act as a reference frame. When the head was tilted to the left, the frame may be considered a rectangular frame tilted $30^{\circ}$ to the left. The values of $\theta$ under this condition differed significantly from $0^{\circ}$ [t(18)

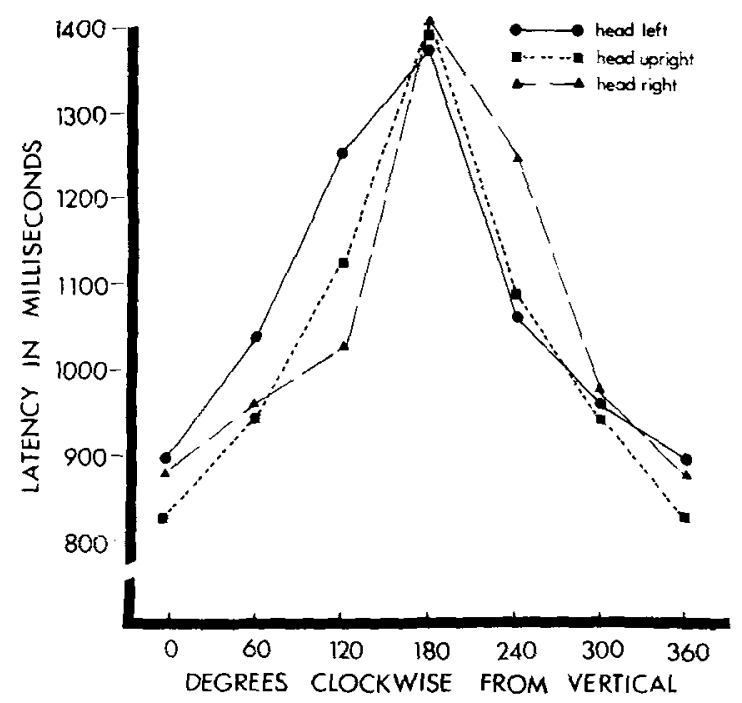

Figure 4. Mean latency as a function of angular orientation of characters for each head tilt in Experiment 3.
Table 3

Estimates of Proportion of Variance $\left(r^{2}\right)$ Due to Mental Rotation Function, Angular Location $(\theta)$ of Subjective Vertical Measured in Degrees Clockwise from the True Vertical, and Rate of Mental Rotation in Degrees per Second in Experiment 3

\begin{tabular}{|c|c|c|c|c|}
\hline Source & $\begin{array}{c}\text { Head } \\
\text { Position }\end{array}$ & $r^{2}$ & $\theta$ & Rate \\
\hline Subject 1 & $\begin{array}{l}\text { Left } \\
\text { Upright } \\
\text { Right }\end{array}$ & $\begin{array}{l}.957 \\
.948 \\
.808\end{array}$ & $\begin{array}{r}-24.8 \\
14.7 \\
16.0\end{array}$ & $\begin{array}{l}434 \\
491 \\
545\end{array}$ \\
\hline Subject 2 & $\begin{array}{l}\text { Left } \\
\text { Upright } \\
\text { Right }\end{array}$ & $\begin{array}{l}.964 \\
.977 \\
.834\end{array}$ & $\begin{array}{r}-2.7 \\
14.3 \\
11.3\end{array}$ & $\begin{array}{l}229 \\
192 \\
166\end{array}$ \\
\hline Subject 3 & $\begin{array}{l}\text { Left } \\
\text { Upright } \\
\text { Right }\end{array}$ & $\begin{array}{l}.932 \\
.965 \\
.760\end{array}$ & $\begin{array}{r}-9.1 \\
13.8 \\
22.0\end{array}$ & $\begin{array}{l}402 \\
349 \\
299\end{array}$ \\
\hline Subject 4 & $\begin{array}{l}\text { Left } \\
\text { Upright } \\
\text { Right }\end{array}$ & $\begin{array}{l}.846 \\
.698 \\
.777\end{array}$ & $\begin{array}{r}-8.6 \\
-6.5 \\
39.4\end{array}$ & $\begin{array}{l}488 \\
501 \\
641\end{array}$ \\
\hline Subject 5 & $\begin{array}{l}\text { Left } \\
\text { Upright } \\
\text { Right }\end{array}$ & $\begin{array}{l}.971 \\
.825 \\
.859\end{array}$ & $\begin{array}{r}-36.2 \\
-24.2 \\
11.0\end{array}$ & $\begin{array}{l}303 \\
249 \\
236\end{array}$ \\
\hline Subject 6 & $\begin{array}{l}\text { Left } \\
\text { Upright } \\
\text { Right }\end{array}$ & $\begin{array}{l}.686 \\
.967 \\
.753\end{array}$ & $\begin{array}{r}-30.4 \\
4.7 \\
-8.8\end{array}$ & $\begin{array}{l}233 \\
162 \\
186\end{array}$ \\
\hline Subject 7 & $\begin{array}{l}\text { Left } \\
\text { Upright } \\
\text { Right }\end{array}$ & $\begin{array}{l}.969 \\
.936 \\
.855\end{array}$ & $\begin{array}{r}-20.1 \\
-\quad 4.6 \\
36.0\end{array}$ & $\begin{array}{l}180 \\
306 \\
199\end{array}$ \\
\hline Subject 8 & $\begin{array}{l}\text { Left } \\
\text { Upright } \\
\text { Right }\end{array}$ & $\begin{array}{l}.613 \\
.580 \\
.403\end{array}$ & $\begin{array}{r}-17.2 \\
6.5 \\
31.4\end{array}$ & $\begin{array}{l}695 \\
365 \\
609\end{array}$ \\
\hline Subject 9 & $\begin{array}{l}\text { Left } \\
\text { Upright } \\
\text { Right }\end{array}$ & $\begin{array}{l}.769 \\
.991 \\
.775\end{array}$ & $\begin{array}{r}-27.1 \\
-13.8 \\
21.7\end{array}$ & $\begin{array}{l}313 \\
362 \\
280\end{array}$ \\
\hline $\begin{array}{l}\text { Averaged } \\
\text { Functions }\end{array}$ & $\begin{array}{l}\text { Left } \\
\text { Upright } \\
\text { Right }\end{array}$ & $\begin{array}{l}.940 \\
.952 \\
.887 \\
\end{array}$ & $\begin{array}{r}-20.1 \\
-\quad .8 \\
15.4\end{array}$ & $\begin{array}{l}311 \\
318 \\
289\end{array}$ \\
\hline
\end{tabular}

$=-5.07, p<.001]$, but also differed from $-30^{\circ}$ $[t(18)=2.70, p<.05]$. Hence, the frame did not act as a reference frame in this condition either, although for three of the subjects (Subjects 5, 6, and 9), the subjective vertical did lie close to the vertical defined by the frame. The subjective vertical also differed significantly from $-60^{\circ}$ (the presumed retinal vertical) $[\mathrm{t}(18)=10.47, \mathrm{p}<.001]$. Finally, the values of $\theta$ obtained with the head upright did not differ significantly from $0^{\circ}$ [t(16) $<1]$, but did differ significantly from both $-30^{\circ}[\mathrm{t}(16)=7.63, \mathrm{p}<.001]$ and $60^{\circ}[\mathrm{t}(16)=$ $-15.40, \mathrm{p}<.001]$, indicating that the frame failed to influence the subjective vertical when the head was upright.

In order to assess the overall influence of the frame in this experiment, we compared the values of $\theta$ obtained when the head was tilted with those obtained in Experiment 1. We measured $\theta$ from the gravitational vertical toward the retinal vertical (i.e., the signs were changed for the left-head-tilt 
condition). Analysis of variance reveals no significant difference between left and right head tilt $[F(1,16)<1]$ and no significant interaction between direction of head tilt and experiments $[F(1,16)<1]$, but the overall difference between experiments was marginally significant $[F(1,16)=$ $4.01, p<.10$ ]. Simple $t$ tests revealed no significant difference between experiments with right head tilt, but the values of $\theta$ with left head tilt were significantly further away from the gravitational vertical in this experiment than in Experiment 1 $[\mathrm{t}(16)=2.13, \mathrm{p}<.05]$. However, it is not clear whether this is due to the influence of the frame or whether the failure to observe an effect of left head tilt in Experiment 1 was simply a Type II error.

There was no evidence for systematic sex differences in any of the estimated parameters. Subjects $1,3,5$, and 8 were women, the rest, men.

\section{Summary}

Despite the presence of the tilted frame, the subjective vertical lay closer to the gravitational than to the retinal vertical, and closer to the gravitational vertical than to the vertical defined by the frame itself. If the frame had any influence at all, it was restricted to the case in which the subjects' heads were tilted left. In this case, the frame was best conceived as tilted $30^{\circ}$ to the left (rather than $60^{\circ}$ to the right), and thus was not aligned with the head tilt.

\section{EXPERIMENT 4}

In this experiment, we essentially repeated the right-head-tilt condition of Experiment 3, except that the subjects were instructed to adopt a subjective reference frame corresponding to that of the tilted frame.

\section{Method}

Subjects. There were 12 subjects, four women and eight men, drawn from the same source as in the first three experiments.

Stimuli. The stimuli, screen, and frame were the same as in Experiment 3.

Procedure. The basic procedure was the same as in Experiments 2 and 3 , with the following modifications. First, the subjects only performed the task with their heads tilted to the right, and were instructed to adopt a subjective reference frame corresponding to that of the tilted frame. They were told that the higher of the two long edges of the frame should be treated as the "top" edge, and that the two short edges (actually rotated $60^{\circ}$ clockwise from the true vertical) should define the subjective upright. All subjects clearly understood the instructions, but several complained later that it was difficult to follow them.

Secondly, the subjects were given two blocks of 72 trials, under different conditions of illumination. In the first three experiments, the light in the testing room had been turned off. A translucent window between the testing room and the equipment room created a fairly low level of illumination between trials, which contrasted with the high level of illumination on the screen when the stimuli were being projected. We felt that this arrangement might possibly have detracted from the effectiveness of the frame in Experiment 3. For one of the two blocks of trials, therefore, the subjects performed the task with the light in the testing room turned on. The reference frame was thus more clearly visible between trials, and the change in illumination caused by projection of the stimuli was diminished. Half of the subjects received for the first block of trials with the light on, while for the remaining six subjects the order was reversed.

\section{Results}

The subjects made an average of $16 \%$ errors when the testing room light was on and $15 \%$ when the light was off. These rather high error rates may reflect the difficulty the subjects experienced in attempting to align their subjective reference frames with that defined by the tilted frame.

Analysis of variance of latencies for correct responses again revealed significant main effects due to version $[F(1,10)=30.19, p<.001]$, and orientation $[F(5,50)=34.55, p<.001]$. There was also a significant interaction between the characters whether the light was on or off $[F(5,50)=3.54$, $p<.01]$, although this is not significant if one adopts conservative degrees of freedom $(1,10)$. There were no other significant effects. Figure 5 shows the mean latencies for each angular orientation, for both conditions of illumination.

Table 4 shows the estimated parameters derived from fitting mental rotation functions. Again, the data seem to conform reasonably well to the hypothesis of mental rotation, except perhaps in the case of Subject 1 whose estimated rates of rotation are

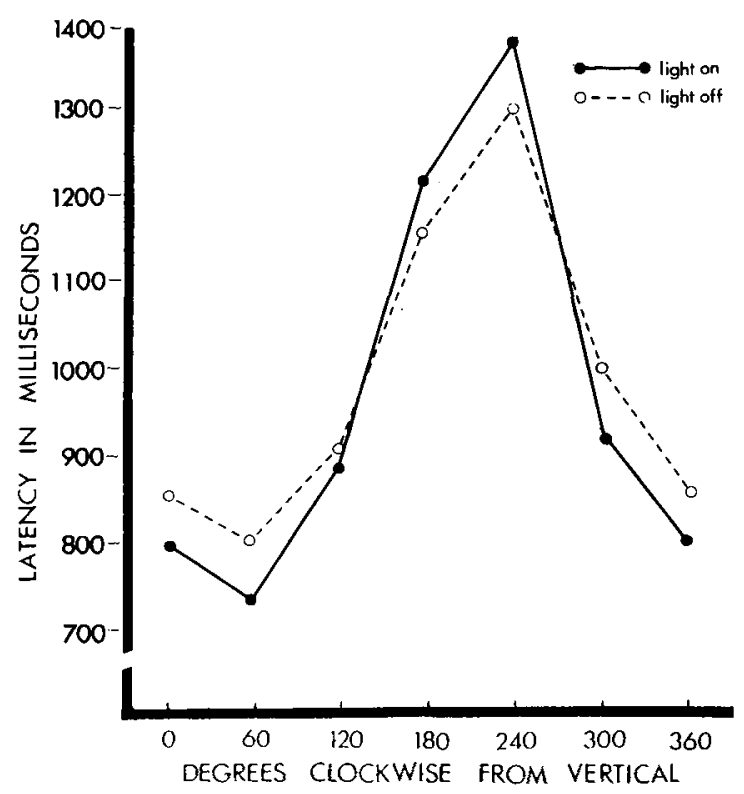

Figure 5. Mean latency as a function of angular orientation of characters for both conditions of illumination in Experiment 4. 
Table 4

Estimates of Proportion of Variance $\left(r^{2}\right)$ Due to Mental Rotation Function, Angular Location $(\theta)$ of Subjective Vertical Measured in Degrees Clockwise from the True Vertical, and Rate of Mental Rotation in Degrees per Second in Experiment 4

\begin{tabular}{|c|c|c|c|c|}
\hline Source & Light & $\mathrm{r}^{2}$ & $\theta$ & Rate \\
\hline Subject 1 & $\begin{array}{l}\text { On } \\
\text { Off }\end{array}$ & $\begin{array}{l}.751 \\
.806\end{array}$ & $\begin{array}{l}22.4 \\
44.8\end{array}$ & $\begin{array}{r}960 \\
1,261\end{array}$ \\
\hline Subject 2 & $\begin{array}{l}\text { On } \\
\text { Off }\end{array}$ & $\begin{array}{l}.848 \\
.795\end{array}$ & $\begin{array}{l}34.3 \\
43.6\end{array}$ & $\begin{array}{l}476 \\
442\end{array}$ \\
\hline Subject 3 & $\begin{array}{l}\text { On } \\
\text { Off }\end{array}$ & $\begin{array}{l}.933 \\
.875\end{array}$ & $\begin{array}{l}30.7 \\
35.7\end{array}$ & $\begin{array}{l}147 \\
192\end{array}$ \\
\hline Subject 4 & $\begin{array}{l}\text { On } \\
\text { Off }\end{array}$ & $\begin{array}{l}.839 \\
.960\end{array}$ & $\begin{array}{l}62.4 \\
77.7\end{array}$ & $\begin{array}{l}148 \\
174\end{array}$ \\
\hline Subject 5 & $\begin{array}{l}\text { On } \\
\text { Off }\end{array}$ & $\begin{array}{l}.920 \\
.865\end{array}$ & $\begin{array}{l}32.3 \\
35.7\end{array}$ & $\begin{array}{l}496 \\
491\end{array}$ \\
\hline Subject 6 & $\begin{array}{l}\text { On } \\
\text { Off }\end{array}$ & $\begin{array}{l}.764 \\
.976\end{array}$ & $\begin{array}{l}44.4 \\
47.3\end{array}$ & $\begin{array}{l}201 \\
272\end{array}$ \\
\hline Subject 7 & $\begin{array}{l}\text { On } \\
\text { Off }\end{array}$ & $\begin{array}{l}.701 \\
.688\end{array}$ & $\begin{array}{l}37.7 \\
20.8\end{array}$ & $\begin{array}{l}229 \\
347\end{array}$ \\
\hline Subject 8 & $\begin{array}{l}\text { On } \\
\text { Off }\end{array}$ & $\begin{array}{l}.927 \\
.978\end{array}$ & $\begin{array}{l}32.4 \\
53.8\end{array}$ & $\begin{array}{l}202 \\
211\end{array}$ \\
\hline Subject 9 & $\begin{array}{l}\text { On } \\
\text { Off }\end{array}$ & $\begin{array}{l}.702 \\
.883\end{array}$ & $\begin{array}{l}48.7 \\
28.8\end{array}$ & $\begin{array}{l}383 \\
575\end{array}$ \\
\hline Subject 10 & $\begin{array}{l}\text { On } \\
\text { Off }\end{array}$ & $\begin{array}{l}.877 \\
.998\end{array}$ & $\begin{array}{l}19.2 \\
33.6\end{array}$ & $\begin{array}{l}215 \\
231\end{array}$ \\
\hline Subject 11 & $\begin{array}{l}\text { On } \\
\text { Off }\end{array}$ & $\begin{array}{l}.833 \\
.484\end{array}$ & $\begin{array}{l}39.4 \\
63.1\end{array}$ & $\begin{array}{l}156 \\
441\end{array}$ \\
\hline Subject 12 & $\begin{array}{l}\text { On } \\
\text { Off }\end{array}$ & $\begin{array}{l}.916 \\
.794\end{array}$ & $\begin{array}{l}46.8 \\
33.7\end{array}$ & $\begin{array}{l}145 \\
193\end{array}$ \\
\hline $\begin{array}{l}\text { Averaged } \\
\text { Functions }\end{array}$ & $\begin{array}{l}\text { On } \\
\text { Off }\end{array}$ & $\begin{array}{l}.910 \\
.947\end{array}$ & $\begin{array}{l}40.0 \\
44.5\end{array}$ & $\begin{array}{l}226 \\
309\end{array}$ \\
\hline
\end{tabular}

implausibly high. It appears also that the values of $\theta$ are larger than in the previous experiments, although only Subject 4 seems to have succeeded completely in making his subjective vertical coincide with that of the frame (and of his own retinal coordinate system), as instructed. Overall, the mean value of $\theta\left(40 \cdot 49^{\circ}\right)$ differs significantly from $0^{\circ}[\mathrm{t}(10)=11.66$, $\mathrm{p}<.001$ ], but it also differs significantly from $60^{\circ}$ $[t(10)=-5.66, p<.001]$. Nevertheless, the mean value of $\theta$ in this experiment is significantly higher than that obtained with right head tilt in Experiment $3[t(18)=2.77, p<.02]$. This indicates that the instructions were at least partially successful, in that they caused the subjects to move their subjective reference frames closer to that of the actual frame.

Subjects $1,2,7$, and 8 were women, the rest, men. Aside from the fact that Subject 1 , a woman, yielded very high estimated rates of mental rotation, there was no evidence for any consistent sex differences.

\section{Summary}

In this experiment, we provided what should have been nearly optimal conditions for subjects to adopt a retinal rather than a gravitational reference system in mentally rotating alphanumeric characters. The stimuli were presented surrounded by a frame, tilted to coincide with the retinal horizontal and vertical axes, and the subjects were instructed to adopt this frame as their reference frame. These conditions produced estimates of a subjective vertical which actually lay closer to the retinal than to the gravitational vertical. With one exception, however, the subjects were still unable to rotate their subjective reference frames into full coincidence with the frame that was physically present.

\section{EXPERIMENT 5}

In the first four experiments, the subjects' heads were either upright or tilted $60^{\circ}$. In this experiment, the subjects performed the task with their bodies rotated $90^{\circ}$ and their heads at either $90^{\circ}$ or $60^{\circ}$ from the gravitational vertical. Our aim was to discover whether more extreme tilt would induce subjects to adopt a retinal reference frame.

\section{Method}

Subjects. There were two parts to this experiment. Four men and four women served as subjects in the first part, and three men and two women served in the second part.

Stimuli. The stimuli, screen, and circular surround were the same as in Experiment 1.

Procedure. The basic procedure was the same as in Experiment 2, with the following modifications. The subjects performed the task while lying down on their right sides. The response box was placed in a position such that the subject could comfortably manipulate the buttons.

In the first part of the experiment, the subjects performed with their heads at $90^{\circ}$ to the gravitational vertical for one block of 72 trials, and propped up at $60^{\circ}$ to the gravitational vertical for another block of 72 trials. The order was counterbalanced. Two of the four subjects in each order condition were male and two were female. In this part of the experiment, the slides were oriented in the same way as in Experiment 1, so that there were no stimuli aligned with the retinal vertical when the subjects' heads were at $90^{\circ}$ to the gravitational vertical. Consequently, we ran five more subjects with the slides rotated $90^{\circ}$, so that the angular orientations were $30^{\circ}, 90^{\circ}, 150^{\circ}, 210^{\circ}$, $270^{\circ}$, and $330^{\circ}$, measured clockwise from the gravitational vertical. In this second part of the experiment, the subjects performed the task only with their heads and bodies tilted $90^{\circ}$ to the right.

\section{Results}

Subjects in the first part of the experiment made an average of $6.75 \%$ errors when their heads were $60^{\circ}$ from the gravitational vertical and $4.25 \%$ errors when their heads were $90^{\circ}$ from the vertical. In the second part of the experiment, the average rate of errors was $5.4 \%$.

For the first part, analysis of variance of the latencies for correct responses revealed again that latencies were significantly shorter for forward than for backward versions $[F(1,4)=17.29, \mathrm{p}<.025]$, 
and that orientation had a significant effect upon latency $[F(5,20)=26.9, p<.001]$. The interaction between head tilt and orientation was only marginally significant $[F(5,20)=2.94, p<.05]$ and insignificant if one adopts conservative degrees of freedom. Sex was included as a variable in this analysis, but that gave rise to no significant effects. In the second part of the experiment, there were significant effects due to both version $[F(1,4)=$ $10.39, p<.05]$ and orientation $[F(5,20)=9.46$, $\mathrm{p}<.001$ ]. Latencies are plotted as a function of orientation and head tilt for each part of the experiment in Figure 6.

Estimated parameters obtained by fitting hypothetical mental rotation functions are shown in Table 5. The estimated rates of mental rotation are somewhat higher than in the previous experiments. In particular, Subject 1 conformed poorly to the hypothesis of mental rotation under the condition of $90^{\circ}$ head tilt. One possible explanation is that there may have been some intraindividual variability in the choice of subjective reference frame. This would have had the effect of flattening the latency function, and thus increasing the estimate of the rate of mental rotation.

The values of $\theta$ obtained in the first half of the experiment did not differ significantly as a function of head tilt $[t(7)=1.713, p>.1]$. However, the mean value obtained with the head tilted $60^{\circ}$ differed both from $0^{\circ}[\mathrm{t}(7)=3.34, \mathrm{p}<.001]$ and

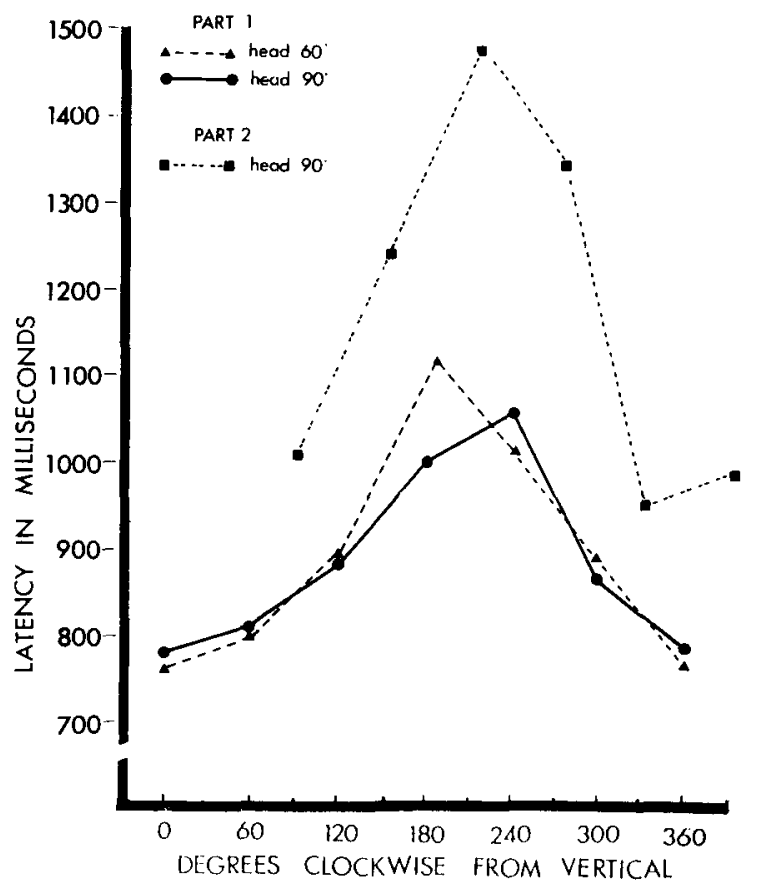

Figure 6. Mean latency as a function of angular orientation of characters for each head tilt in Experiment 5.
Table 5

Estimates of Proportion of Variance $\left(\mathrm{r}^{2}\right)$ Due to Mental Rotation Function, Angular Location ( $\theta$ ) of Subjective Vertical Measured in Degrees Clockwise from the True Vertical, and Rate of Mental Rotation in Degrees per Second in Experiment 5

Part 1

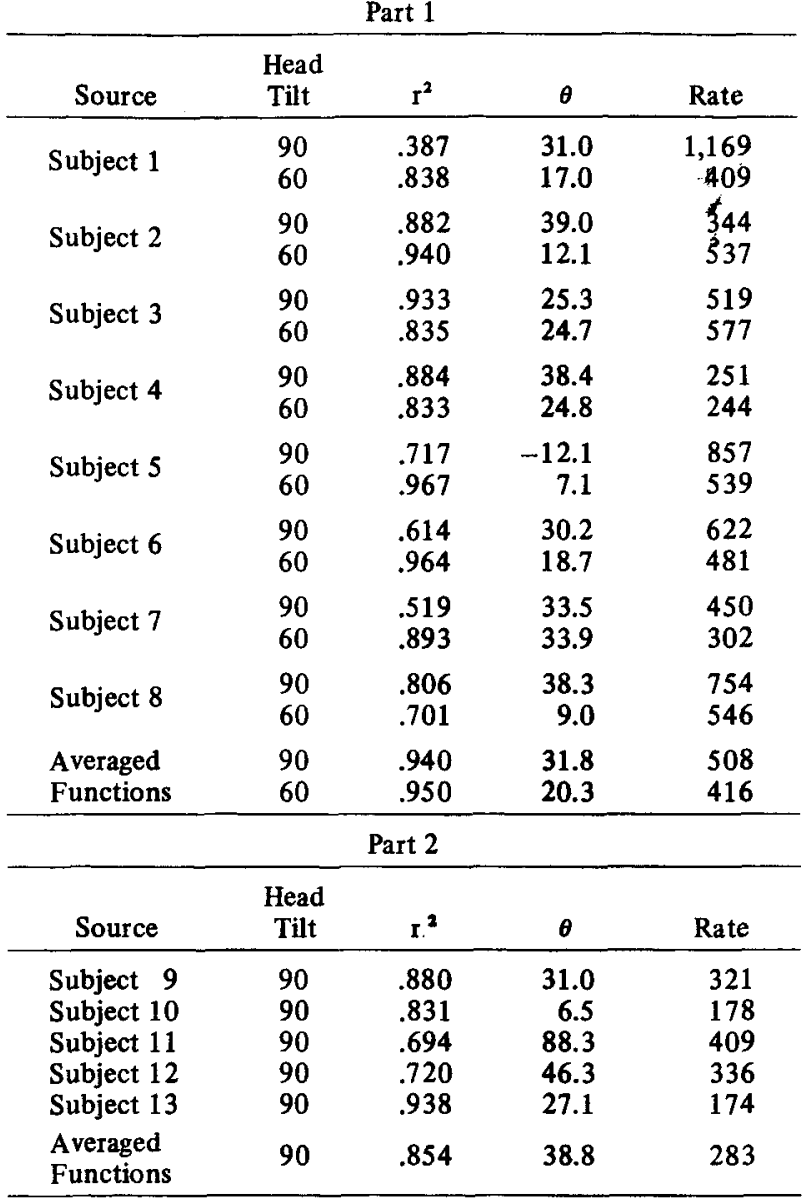

Note-Head tilt is given in degrees.

from $60^{\circ}[t(7)=7.54, p<.001]$. It did not differ significantly from the mean value obtained in Experiment 1 when the head was tilted $60^{\circ}$ to the right of the gravitational vertical $[\mathrm{t}(15)<1]$. The mean value of $\theta$ obtained with the head tilted $90^{\circ}$ to the right differed significantly from both $0^{\circ}$ $[\mathrm{t}(7)=3.34, \mathrm{p}<.02]$ and from $90^{\circ}[\mathrm{t}(7)=11.18$, $\mathrm{p}<.001]$. That is, the subjective vertical lay between the gravitational and the retinal vertical, although closer to the former than to the latter, even when the head was tilted $90^{\circ}$.

In the second part of the experiment, the mean value of $\theta$ also differed significantly from $0^{\circ}$ $[\mathrm{t}(4)=3.90, \mathrm{p}<.02]$ and $90^{\circ}[\mathrm{t}(4)=4.91, \mathrm{p}<.01]$, but did not differ significantly from the mean value obtained in the first part of the experiment with the head tilted $90^{\circ}[t(11)<1]$. Nevertheless, it is noteworthy that one subject, Subject 1 , did seem to 
operate within retinal rather than gravitational coordinates.

\section{Summary}

Even with the body and head tilted $90^{\circ}$, the subjective vertical remained closer overall to the gravitational than to the retinal vertical. Only one subject apparently adopted retinal coordinates. Two subjects (Subjects 5 and 10) adopted a coordinate system close to the gravitational one. For the rest, the subjective vertical ranged between $25^{\circ}$ and $46^{\circ}$ from the gravitational vertical.

\section{DISCUSSION}

In judging whether a symbol is normal or backward, subjects typically mentally rotate some internal representation of it to the "upright" before making their judgment. The experiments reported here demonstrate, over a range of conditions, that the "upright" is more closely aligned with the gravitational than with the retinal vertical. This broadly confirms the results reported by Corballis et al. (1976) on the mental rotation of alphanumeric characters, and is in line with evidence reported by Attneave and Olson (1967) that latency to discriminate horizontal and vertical from oblique lines is a funcion of physical rather than retinal orientation. However, it still leaves open the question of why judgments of symmetry (Corballis \& Roldan, 1975) and repetition (Corballis et al., 1976) are tied more closely to retinal than to gravitational coordinates.

But although the subjective vertical generally lay closer to the retinal than to the gravitational vertical under the head-tilt conditions in our experiments, it was seldom actually aligned with it. This misalignment cannot be attributed simply to the Aubert effect-a constant error which occurs when tilted observers attempt to set a line to the vertical in the absence of other visual cues (Aubert, 1861). For head and body tilts up to about $60^{\circ}-80^{\circ}$, the apparent vertical is misplaced a few degrees from the true vertical in the direction opposite to the tilt of the subject (Bauermeister, 1964; Day \& Wade, 1969). Thus with the head tilted $60^{\circ}$, the effect would be very slight, and if anything in the direction opposite to the location of the subjective vertical in our experiments. The Aubert effect may conceivably have contributed to the location of the subjective vertical in Experiment 5 when the subjects were tilted $90^{\circ}$, for with this degree of tilt the effect is in the same direction as the tilt and may be as high as $10^{\circ}-20^{\circ}$ (Rock, 1973). However, the location of the subjective vertical in Experiment 5 was some $30^{\circ}-40^{\circ}$, on average, from the gravitational vertical. Thus, the Aubert effect cannot explain the total discrepancy between the subjective and gravitational vertical, but it may perhaps explain why the discrepancy was larger than when the head was tilted $90^{\circ}$ than when it was tilted $60^{\circ}$. In general, therefore, our results reinforce the view that the subjective reference frame is distinct from either the retinal or the gravitational reference frame (cf. Rock, 1956; Rock \& Leaman, 1963).

If the subjective upright in our experiments was not tied to the observer's estimate of where the true vertical lay, we may suppose that it was to some extent under voluntary control. This may partly explain the individual differences. Moreover, Experiment 4 showed that subjects could bring their subjective reference frames closer to the retinal reference frame if explicitly instructed to do so. Similarly, Attneave and Reid (1968) found that latency to discriminate horizontal and vertical from oblique lines was a function of retinal rather than gravitational coordinates if the subjects were explicitly instructed to adopt a retinal reference frame. But, although our subjects did manage to bring the subjective vertical closer to the retinal than to the gravitational vertical, only one managed to actually align the subjective vertical with the gravitational vertical, and the average discrepancy was still some $20^{\circ}$, even though a physical reference frame aligned with retinal axes was continuously visible. This suggests that subjects have somewhat limited control over the subjective reference frame in the mental rotation of alphanumeric charactersmore limited perhaps than in the task studied by Attneave and Reid. In this context, we may note that, in their studies of the mental rotation of alphanumeric characters, Cooper and Shepard (1973) found that subjects were unable to modify their subjective reference frames in response to prior information about the orientation of each test character.

Finally, our results have some implications concerning the so-called "retinal factor" in the perception of orientation, postulated by Rock (1973). He argued that patterns are first perceived according to retinal coordinates, but are "more or less immediately" corrected to compensate for head tilt or for tilt of the pattern itself. Our results, as well as those of Attneave and Olson (1967), make it seem unlikely that the compensation for head tilt occurs after presentation of the pattern, since the subjects made speeded judgments within axes corresponding more closely to gravitational than to retinal coordinates without any evident increase in latency. It is more likely that the reference frame is established prior to the presentation of the pattern. Clearly, this arrangement would lead to much more efficient perception of the world, for it would be both confusing and time-consuming if every retinal image had to be separately corrected for head tilt; on the contrary, the smooth flow of 
perceptual experience continues undisturbed when we tilt our heads. Rock's argument was based on the grounds that there are certain situations in which retinal coordinates seem to have proirity. For instance, certain complex patterns are difficult to recognize if one turns one's head upside down, and become recognizable only if the patterns themselves are inverted. Again, subjects adopt a retinal frame of reference in the absence of any gravitational influence, as when a pattern is displayed horizontally and viewed from above. Finally, subjects with their heads upright may first interpret a tilted pattern within a retinal framework, but one could just as well argue here that it is the gravitational framework which has priority, since the two coincide. We suggest that it is the subjective framework which has priority, but that there are some circumstances in which this framework is aligned with the retinal framework, some in which it is aligned with the gravitational framework, and some in which it is aligned with neither. In this, we concur with such authors as Gibson (1966), Neisser (1976), and Turvey (1977), who argue that the retinal image per se has little direct role in determining the coordinates of spatial perception.

\section{REFERENCES}

Attneave, F., \& Olson, R. Discriminability of stimuli varying in physical and retinal orientation. Journal of Experimental Psychology, 1967, 74, 149-157.

Attneave, F., \& Reid, K. Voluntary control of frame of reference and slope equivalence under head rotation. Journal of Experimental Psychology, 1968, 78, 153-159.

Aubert, H. Eine scheinbare bedeutende Drehung von Objekten bei Neigung des Kopfes nach rechts odor links. Virchows Archiv für pathologische Anatomie und Physiologie und fur Klinische Medizin, 1861, 20, 381-393.

BAUERMEIsTER, M. Effect of body tilt on apparent verticality, apparent body position, and their relation. Joumal of Experimental Psychology, 1964, 67, 142-147.
CoOper, L. A., \& Shepard, R. N. Chronometric studies of the rotation of mental images. In W. G. Chase (Ed.), Visual information processing. New York: Academic Press, 1973.

Corballis, M. C., \& Roldan, C. E. Detection of symmetry as a function of angular orientation. Journal of Experimental Psychology: Human Perception and Performance, 1975, 1 , 221-230.

Corballis, M. C., Zbrodoff, J., \& Roldan, C. E. What's up in mental rotation? Perception \& Psychophysics, 1976, 19. 525.530.

DAY, R. H., \& WADE, N. J. Mechanisms involved in visual orientation constancy. Psychological Bulletin, 1969, 71, 33-42.

Gibson, J. J. The senses considered as perceptual systems. Boston: Houghton Mifflin, 1966.

MilleR, E. F. Counterrolling of the human eyes produced by head tilt with respect to gravity. Acta Oto-Laryngologica, $1962,54,479-501$.

NeISSER, U. Cognition and reality. San Francisco: Freeman, 1976.

Rock, I. The orientation of forms on the retina and in the environment. American Journal of Psychology, 1956, 69, 513-528.

Rock, I. Orientation and form. New York: Academic Press, 1973.

Rock, I., \& LEAman, R. An experimental analysis of visual symmetry. Acta Psychologica, 1963, 21, 171-183.

ShePARd, R. N., \& METzLeR, J. Mental rotation of threedimensional objects. Science, 1971, 171, 701-703.

TuRveY, M. T. Contrasting orientations to the theory of visual information processing. Psychological Review, 1977, 84, 67-88.

WINER, B. J. Statistical principles in experimental design. New York: McGraw-Hill, 1971.

\section{NOTE}

1. Subject samples were equated as nearly as possible for sex (i.e., four of one sex, five of the other) in Experiments 1 and 2. Due to an oversight, however, records of the sex of individual subjects were not kept. There was no evidence for consistent sex differences in Experiments 3, 4, and 5, where records were maintained.
(Received for publication August 16, 1977; revision accepted May 25, 1978.) 